\title{
Morphological characterization of the antennal lobes in the Mediterranean fruit fly Ceratitis capitata
}

\author{
Paolo Solari $^{1}$ - Valentina Corda ${ }^{1}$ - Giorgia Sollai $^{1} \cdot$ Sabine Kreissl $^{2}$ \\ C. Giovanni Galizia ${ }^{2} \cdot$ Roberto Crnjar ${ }^{1}$
}

\begin{abstract}
The medfly Ceratitis capitata is one of the most important pests for horticulture worldwide. The knowledge about anatomy and function of the medfly olfactory system is still limited. The first brain structure to process olfactory information in insects is the antennal lobe (AL), which is composed of its functional and morphological units, the olfactory glomeruli. Here, we present a morphological three-dimensional reconstruction of AL glomeruli in adult brains. We used unilateral antennal backfills of olfactory receptor neurons (ORNs) with neural tracers, revealing the AL structure. We recorded confocal stacks acquired from whole-mount specimens, and analyzed them with the software AMIRA. The ALs in C. capitata are organized in glomeruli which are more tightly packed in the anterior part than the posterior one. Axons of ORNs bilaterally connect the ALs through a commissure between the two ALs. This commissure is formed by several distinct fascicles. Contralateral dye transfer suggests the presence of gap junctions connecting ORNs from both antennae. There was no statistical difference between the average volumes of female ALs $\left(204,166 \pm 12,554 \mu \mathrm{m}^{3}\right)$ and of male ALs
\end{abstract}

P. Solari and V. Corda are contributed equally to this work.

Roberto Crnjar

crnjar@unica.it

1 Department of Biomedical Sciences, Section of Physiology, University of Cagliari, University Campus, S.P. 8, 09042 Monserrato, CA, Italy

2 Department of Neurobiology, University of Konstanz, 78457 Constance, Germany $\left(190,287 \pm 11,823 \mu \mathrm{m}^{3}\right)$. In most specimens, we counted 53 glomeruli in each AL, seven of which were sexually dimorphic in size.

Keywords Ceratitis capitata $\cdot$ Glomeruli $\cdot$ Antennal backfill $\cdot$ Immunohistochemistry $\cdot$ 3D reconstruction

\begin{tabular}{ll}
\multicolumn{2}{l}{ Abbreviations } \\
AL & Antennal lobe \\
AMMC & Antennal mechanosensory and motor center \\
DAPI & $4^{\prime}$,6-Diamidino-2-phenylindole \\
MCG & Macroglomerular complex \\
NB & Neurobiotin \\
ORN & Olfactory receptor neuron \\
SEG & Subesophageal ganglion \\
SIT & Sterile insect technique \\
TMR-DA & Tetramethylrhodamine-conjugated dextran \\
& amine \\
VUM & Ventral unpaired median
\end{tabular}

\section{Introduction}

The Mediterranean fruit fly Ceratitis capitata (Wied.) is a widespread pest for horticulture, targeting a great variety of fruit and vegetables species (Liquido et al. 1990). It is considered one of the most important agricultural pests in the world not only for its broad polyphagy, but also because of its biological potential, the possibility of adaptation to diverse environments and the difficulty of control (Gasperi et al. 2002; Malacrida et al. 2007; De Meyer et al. 2008; Diamantidis et al. 2011). Due to its commercial relevance, many studies focused on the development and improvement of different control strategies. Some of them are based on the use of biological competitors (Headrick and Goeden 
1996) or sterile adults, as in the Sterile Insect Technique (SIT, Shelly and Kennelly 2002; Shelly and McInnis 2003; Shelly 2005), others on chemicals, such as the mass trapping (Jang et al. 1989, 1994; Heath et al. 1991; Cossè et al. 1995; Katsoyannos et al. 1997; Papadopoulos et al. 2001). Both SIT and mass trapping are more effective when they involve the activation of the olfactory system, since odorants can be used as efficient species-specific attractants. Knowledge of the morphological and functional properties of the peripheral and central olfactory structures is a fundamental requirement to understand the mechanisms involved in odor information processing.

Several studies have been conducted in the past years on olfactory sensitivity of $C$. capitata toward different compounds of interest for this species. For example, electrophysiological recordings from antennae of medfly adults have shown a higher sensitivity of females than males for some Citrus peel oils and volatile compounds (Light et al. 1988, 1992; Levinson et al. 1990; Hernandez et al. 1996), while behavioral tests revealed a stronger preference of males than females for the volatiles of orange flavedo (Katsoyannos et al. 1997). In females, odor preference may be affected by mating behavior: it has been observed that females are more attracted by the male-produced pheromone than the ripe guava odor during early sexual maturity, but this preference is inverted after mating (Jang 1995). Furthermore, the exposure to some natural and synthetic compounds may influence the mating behavior in medfly males (Shelly et al. 1996, 2004, 2007, 2008).

From a morphological point of view, information about the olfactory system of $C$. capitata in the literature is dramatically incomplete. The peripheral structures in adult medflies have so far been described best, with particular attention to the typology and distribution of olfactory chemosensilla on the antennal surfaces of males and females. Briefly, four sensilla types (classified as basiconic, clavate, trichoid, and grooved) are distributed along the antennal flagellum (Mayo et al. 1987; Crnjar et al. 1988; Bigiani et al. 1989; Sollai et al. 2010). There is no sexually dimorphic difference in number and distribution, except for clavate sensilla, which are more frequent in the lateral surface of females (Sollai et al. 2010). Olfactory sensilla house the olfactory receptor neurons (ORN) that transduce information of a volatile stimulus into action potentials. Past the peripheral morphology, little is known about the olfactory structures in the central nervous system of this species.

Olfactory receptor neurons on the insect antenna project their axons into the brain. Their target area is the first brain center in which olfactory information is processed: the antennal lobe (AL), analogous in structure and function to the olfactory bulb of vertebrates (Strausfeld and Hildebrand 1999). ORN axons terminate in spherical structures within the AL, called olfactory glomeruli, where they synapse with the neurites of target neurons (local interneurons and projection neurons). Local interneurons process olfactory information within glomeruli and across them, projection neurons relay information processed inside the ALs to the higher brain centers, the mushroom body calyces and lateral horn (Homberg et al. 1988, 1989; Stocker 1994; Ito et al. 1998; Galizia and Rössler 2010; Galizia 2014).

Across many species, the functional organization of the AL is conserved (Galizia 2008), while the number of glomeruli is variable depending on the species (Rospars 1988; Schachtner et al. 2005). Importantly, glomeruli form the functional units of the olfactory code at this level of processing. Odors are coded as combinatorial patterns of activity across glomeruli, with some odorants activating one or few glomeruli selectively, and others eliciting complex patterns across glomeruli (Galizia 2014). In a combinatorial system, information capacity scales superexponentially with the number of units present. Therefore, knowing how many glomeruli a species has is an indication for the dynamic range of how many odors can be coded at best in the system. Furthermore, glomeruli with related response profiles are often clustered, suggesting that lateral processing across glomeruli may be influenced by their relative position (Knaden et al. 2012). Knowing the spatial arrangement of glomeruli thus becomes a relevant step in elucidating the olfactory system of a particular species. For this reason, the glomerular organizations of the ALs have been studied and described in several insect species, such as Drosophila (Stocker et al. 1990; Laissue et al. 1999), moths (Kanzaki et al. 1989; Rospars and Hildebrand 1992; Berg et al. 2002; Skiri et al. 2005), honeybees (Galizia et al. 1999), mosquitoes (Anton and Rospars 2004; Ignell et al. 2005; Ghaninia et al. 2007), cockroaches (Chiang et al. 2001) and beetles (Dreyer et al. 2010; Hu et al. 2011). This development has been strongly aided by the improvement of staining techniques based on fluorescent dyes, combined with confocal sectioning of whole-mount preparations, and the reconstruction of entire ALs by image analyses.

Since no data are available for $C$. capitata, the aim of this work was to characterize the glomerular morphology of the ALs in adult medfly brains. For this purpose, unilateral antennal backfills in combination with immunohistochemical staining were performed in adult males and females. We compared different neuronal tracers and added counterstains in some preparations. Confocal stacks acquired from whole-mount specimens were analyzed, and we report the number of glomeruli, their sizes and relative positions. Most importantly, the 3D atlas is available as an interactive tool to the community, in the hope that it be helpful for future researchers. 


\section{Materials and methods}

\section{Insects}

All the experiments were performed on adult medflies of C. capitata of both sexes (5-10 days old), kindly supplied by the Dept. of Animal Biology of the University of Pavia (Italy) at the pupal stage, and reared under controlled conditions $\left(22 \pm 1{ }^{\circ} \mathrm{C}, 60-70 \%\right.$ relative humidity, 12:12 h light:dark cycle) in a climatic chamber. Adult flies were fed with a mixture of sugar and yeast (4:1). Fresh water was given twice a week.

\section{Staining techniques}

Three different staining techniques were used. First, unilateral antennal backfills (right antenna) were performed in eight females, by means of the neuronal tracer neurobiotin (NB, Vector Laboratories), revealed by streptavidin conjugated with the fluorochrome Cy3 (Jackson ImmunoResearch Europe). Second, NB was used as a backfilled tracer, and visualized with avidin-Alexa Fluor 488 (Invitrogen, Molecular Probes) ( $n=8$ males, $n=4$ females). In some specimens ( $n=4$ males, $n=2$ females) we added immunohistochemical labeling with the primary antibody anti-synapsin (anti SYNORF1 3C11, Developmental Studies Hybridoma Bank, University of Iowa, USA), in order to visualize brain areas with high synaptic density (such as the glomeruli in the ALs). We incubated with a goat anti-mouse secondary antibody conjugated with Alexa Fluor 546 (Invitrogen, Molecular Probes). Cell nuclei were visualized with 4',6-diamidino-2-phenylindole (DAPI). Third, bilateral or unilateral (right) antennal backfills were performed using the neuronal tracer tetramethylrhodamine-conjugated dextran amine (TMR-DA; Molecular Probes, D3308, MW 3000) ( $n=3$ males and $n=3$ females).

Except otherwise stated, chemicals were purchased from Sigma-Aldrich.

\section{Antennal backfills}

Living insects were inserted into truncated $100 \mu$ plastic pipette tips, with the head protruding at the tip and immobilized with plasticine. Then, the right antenna was placed vertically and stabilized with other plasticine. A small well was built around the antenna with vaseline, filled with a drop of a NB solution (2\% in distilled water), and the antenna was cut at the base of the flagellum, exposing the cut surface to the tracer solution.

The well was then covered with more vaseline and the insects were kept at $4{ }^{\circ} \mathrm{C}$ in a moistened chamber to prevent desiccation, for $5 \mathrm{~h}$ or overnight, to allow complete migration of the tracer. Afterward, heads were removed from the insect body, and placed in a Petri dish with $4 \%$ paraformaldehyde dissolved in sodium phosphate buffer (PBS, 0.1 M, pH = 7.2). The brains were immediately dissected from the head capsule and post-fixed in new fresh paraformaldehyde at room temperature, for a total fixation time of $3 \mathrm{~h}$. Subsequently, brains were washed several times (usually 8 times $\times 30 \mathrm{~min}$ ) in PBS with $0.2 \%$ Triton $\mathrm{X}-100$ (PBST). Brains were then incubated in avidin-Alexa Fluor 488 at 1:400 dilution or in streptavidin-Cy3 at 1:500 dilution for 3 days. The nuclear marker DAPI (1:500) was added together with avidin or streptavidin for visualization of cell body nuclei. After incubation, brains were washed in PBST ( 8 times $\times 30 \mathrm{~min}$ ), dehydrated in increasing ethanol solutions $(50 \%, 75 \%, 95 \%, 2$ times $\times 100 \%, 30 \mathrm{~min}$ each) and treated in xylene for 2-3 min.

The same procedure was adopted also for bilateral or unilateral (right) antennal backfills with TMR-DA, except for the visualization steps with avidin-Alexa Fluor 488, streptavidin-Cy3 or DAPI.

All the steps of fixation, washing and incubation were done on a shaker, in constant and gentle agitation. Finally, brains were mounted in DPX (a mixture of distyrene, a plasticizer, dissolved in toluene-xylene), using three spacer rings (Secure-Seal ${ }^{\mathrm{TM}}$ imaging spacers, $13 \mathrm{~mm}$ diameter $\times 0.12 \mathrm{~mm}$ depth, Sigma-Aldrich) to avoid pressure effects on the brain tissues by the coverslip. In fact, the thickness of the brain in the mid region, where the ALs are located, is about $300 \mu \mathrm{m}$, less than the thickness of the triple spacers $(360 \mu \mathrm{m})$ used. Any possible compression due to the coverslip was thus absorbed by the spacers, leaving the AL region unaffected.

\section{Immunohistochemistry}

Six specimens were additionally labeled for synapsin, to visualize the neuropil. In these preparations, after the NB backfill step, brains were treated with a blocking solution of PBST containing $0.2 \%$ bovine serum albumin (BSA) and $0.02 \% \mathrm{NaN}_{3}$. The blocking step was done at room temperature on a shaker, for $12 \mathrm{~h}$ or overnight, to prevent unspecific binding of the antibody and to reduce the background noise. Then, brains were incubated in a solution with avidin-Alexa Fluor 488 (1:400) and the mouse monoclonal primary antibody anti-synapsin $(1: 250)$ in PBST with $0.2 \% \mathrm{BSA}$ and $0.02 \% \mathrm{NaN}_{3}$. The specimens were subsequently washed (8 times $\times 30 \mathrm{~min})$ in PBST and incubated in a goat anti-mouse secondary antibody conjugated with Alexa Fluor 546, diluted 1:200, and DAPI (1:500) in PBST with $0.2 \% \mathrm{BSA}$ and $0.02 \% \mathrm{NaN}_{3}$. After incubation, brains were washed again in PBST ( 8 times $\times 30 \mathrm{~min}$ ), dehydrated in increasing ethanol solutions (50-100\%, $30 \mathrm{~min}$ 
each), treated with xylene (2-3 min), and finally mounted in DPX.

\section{Image acquisition and analysis}

3D-Images from whole-mount specimens were obtained by confocal microscopy.

Brains treated with streptavidin-Cy3 (eight female brains) were scanned with a Zeiss LSM 510 Meta confocal microscope (Carl Zeiss, Jena, Germany), equipped with a $20 \times, \mathrm{NA}=1.0$ water immersion objective for full brain scans, and a $63 \times, \mathrm{NA}=1.4$ oil objective for single AL scans. Cy3 was excited with a HeNe laser at $543 \mathrm{~nm}$, whereas DAPI was excited in 2-photon mode at $750 \mathrm{~nm}$, with appropriate filters to detect the fluorescence.

Preparations treated with Alexa Fluor 488, Alexa Fluor 546 and TMR-DA were viewed with a Leica SP5 confocal microscope, using a $20 \times / 0.5$ dry or a $63 \times / 1.40$ oil objective. A supercontinuum white light laser delivered an excitation wavelength of $488 \mathrm{~nm}$ for Alexa Fluor 488, and $556 \mathrm{~nm}$ for Alexa Fluor 546 and TMR-DA. Fluorescence was detected in a range of 495-580 and 561$635 \mathrm{~nm}$, respectively. Nuclei stained with DAPI were excited with a UV laser (405-diode). The voxel size was $0.2405 \times 0.2405 \times 0.25177 \mu \mathrm{m}(x, y, z)$.

\section{Glomerular identification and nomenclature}

20 3D image stacks were analyzed with the AMIRA 5.2.1 software (Visage Imaging, Berlin, Germany). Glomeruli were labeled using the Segmentation tool. Identification of glomeruli in the medfly ALs was made considering the location, the shape and the dimension, and the nomenclature used is based on that developed for Drosophila (Stocker et al. 1990). Each glomerulus was marked by one or two capital letters indicating the general position: $\mathrm{A}=$ anterior, $\mathrm{P}=$ posterior, $\mathrm{D}=$ dorsal, $\mathrm{V}=$ ventral, $\mathrm{L}=$ lateral, $\mathrm{M}=$ medial, $\mathrm{C}=$ central. Letters were followed by numbers to distinguish multiple glomeruli in the same region.

Six brains stained with TMR-DA were also scanned and qualitatively analyzed for their overall AL morphology with AMIRA 5.2.1.

\section{Statistics}

For each AL, the following parameters were measured: volume of glomeruli, overall volume of the AL (expressed as the sum of the volumes of all stained glomeruli in a given $\mathrm{AL}$ ) and sex of the animal. Volumes of glomeruli were calculated after the segmentation procedure, multiplying the number of voxels with size of a single voxel.

Since NB unilateral (right) antennal backfills resulted in staining of not only the ipsilateral (right) ALs, but also of the contralateral (left) ALs, two-way ANOVA was used to evaluate volumetric differences between ipsilateral and contralateral ALs within each sex and between corresponding ALs in males and females.

To investigate sexual dimorphism in glomerular size, two-way ANOVA was used to compare, within ipsilateral ALs, the volume of each glomerulus type across sex. To this purpose, the glomerulus volumes were linearly normalized to the total volume of each respective AL.

Data were checked for the assumption of normality and homogeneity of variance, and post hoc comparisons were conducted with the Duncan's test. All statistical analyses were performed using STATISTICA for WINDOWS (version 7.0; StatSoft Inc., Tulsa, OK, USA). $P$ values $<0.05$ were considered significant.

\section{Results}

\section{Backfills and antibody stainings}

Confocal sectioning of $C$. capitata brains allowed us to visualize entire ALs in single image stacks. Optical penetration was sufficient to achieve good image quality across the entire depth of the AL (Fig. 1a). For quantitative image analysis, we selected the 20 brains with best image quality across the entire image stack. Six of these were also immunostained for synapsin both in the left and the right ALs (Fig. 1b, c). As other insects, medflies have two ALs, symmetrically located in the anterior part of the brain (Fig. 1d). The shape of the ALs was ellipsoidal and flattened (Fig. 2). We took great care to ascertain that the flat shape was not a consequence of artificial compression, but rather a genuine property of this species' neuroanatomy. The left and right AL were interconnected by a commissure formed by ORN axons which were arranged in multiple nerve fascicles (Fig. 2a). ORNs form a commissure also in Drosophila (Stocker 2001), but not in all Diptera; e.g. not in mosquitoes (Ghaninia et al. 2007) or Phormia regina (Calliphoridae) (Larsen et al. 1976); but in some mosquito ORNs on the palps project bilaterally (Anton et al. 2003).

Tracing neurons from the antenna reliably labeled afferences to the ipsilateral and the contralateral AL. In addition, irrespective of the tracer used, we found several other structures labeled from the antenna. These include (see supplementary Figure): (1) a group of cell bodies (between 2 and 4) that were labeled in the subesophageal ganglion (SEG), connected by prominent axons. This label was strong in some samples, and weak in others, possibly depending on how well the tracer was transported; (2) a mesh of neuropil in the SEG, indicating the presence of gustatory sensory neurons; (3) staining of fibers in the antennal mechanosensory and motor center (AMMC) of the dorsal lobe, adjacent 

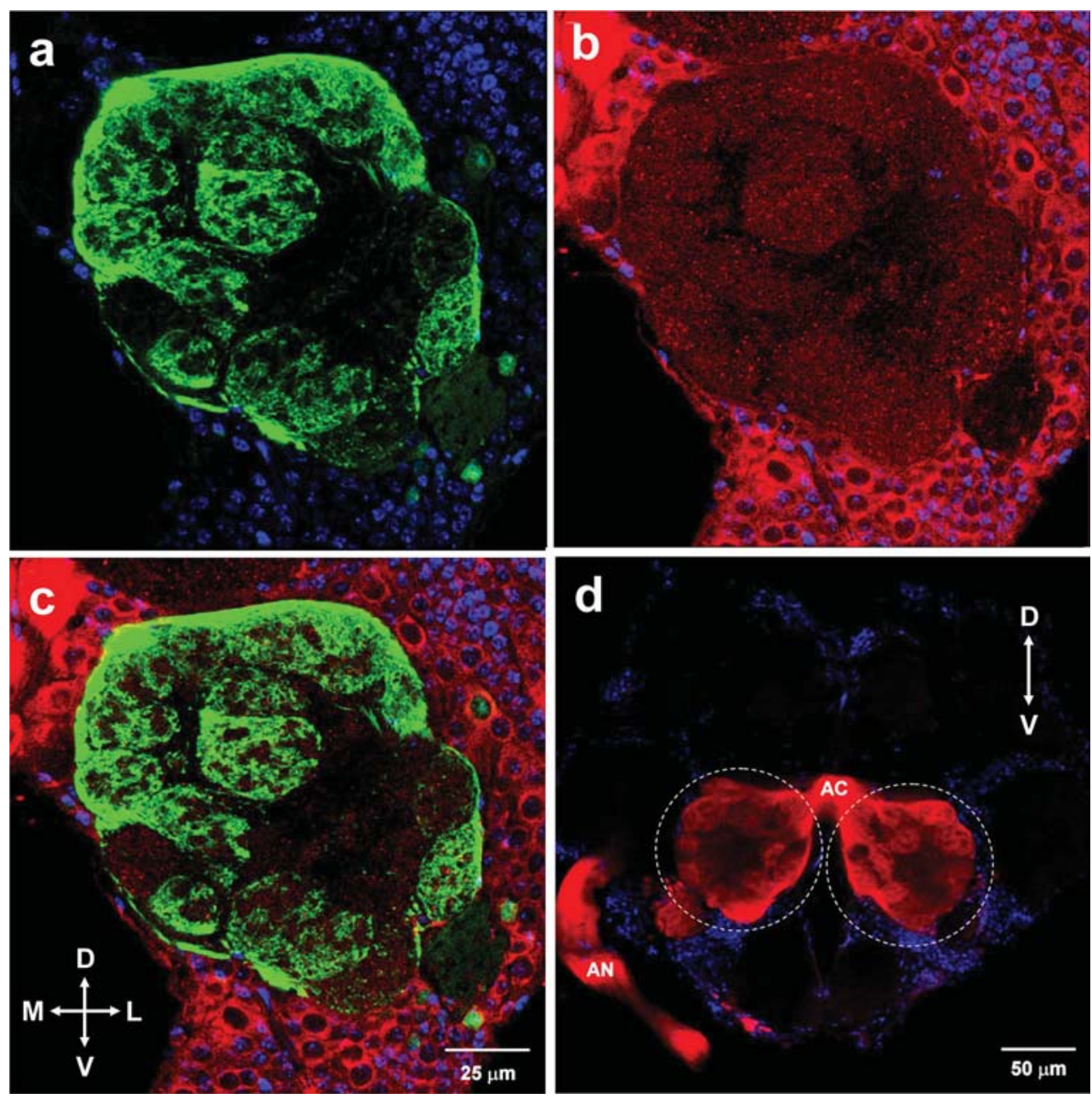

Fig. 1 Single optical sections of an AL in an adult medfly. a Anterograde backfill with neurobiotin (NB, green), revealed by avidin-Alexa Fluor 488. Projections of ORNs enter the AL and form dense packed regions identifiable as glomeruli. DAPI (blue) stains cell body nuclei. b Immunohistochemical staining with anti-synapsin antibody (red) allowed to highlight the presence of glomeruli inside the ALs, and clusters of cell bodies surrounding the AL (nuclei stained with DAPI, blue). $\mathbf{c}$ NB and anti-synapsin stainings merged together from a and

to the AL (Ito et al. 2014). Interestingly, no cell bodies of motor neurons were labeled in this area, suggesting that our distal cut of the antennal nerve did not include motor neuron fibers; (4) a single neurite bypassing the AL and projecting into the protocerebrum along the brain midline. Since in this study we focus on the AL, we did not consider these projections in further detail. In addition, we found that when we used NB as tracer, additional cells and neurites were labeled weakly, but clearly visible. In particular, the contralateral antennal nerve was also labeled, and more contralateral glomeruli were labeled. In addition, we found NB staining in cell bodies adjacent the AL (local neurons and projection neurons), and several second-order projections (e.g. from the $\mathrm{AL}$ to the mushroom bodies).

b. Comparison of the two stainings was fundamental in some cases, to recognize the borders of single glomeruli otherwise not identifiable. d Anterograde backfill in a specimen treated with NB revealed by streptavidin-Cy3. Sensory afferents from ORNs enter the AL, forming the antennal nerve (AN). Due to a contralateral innervation, ALs are interconnected by the antennal commissure (AC). The nuclear marker DAPI revealed the cell body nuclei. The orientation of the AL is indicated: $D$ dorsal, $V$ ventral, $L$ lateral, $M$ medial

\section{The antennal lobes of Ceratitis capitata: identification of glomeruli and statistics}

We reconstructed each glomerulus in the image stacks of the NB-stained AL (Fig. 3) and found that, in each sex, 53 glomeruli were present in both the ipsilateral and contralateral ALs. Missing or supernumerary glomeruli were only occasionally found. However, we also found that backfills from the antenna did not stain all glomeruli: a number of glomeruli were evident in the immunohistochemical staining with anti-synapsin antibody, but not labeled by NB. These glomeruli appear as interspersed among those backfilled by NB throughout the antenna (Fig. 4). The synapsin labeling alone did not give us sufficiently clear information 

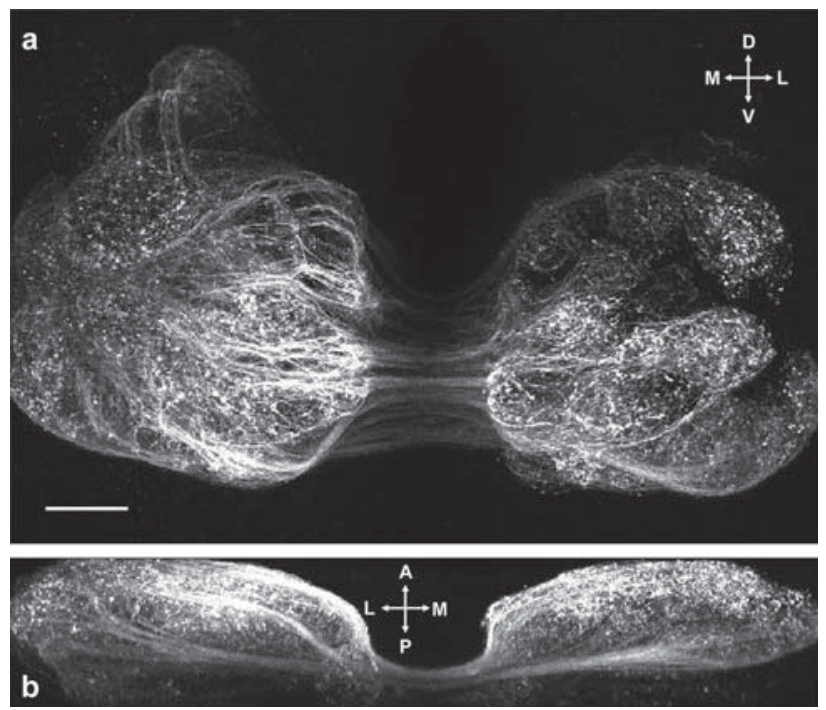

Fig. 2 Confocal XY (a) and XZ (b) planar projection view of a representative preparation following unilateral antennal backfills with TMR-DA, showing the ellipsoidal (a) and flattened (b) shape of ALs and the commissure formed by multiple nerve fascicles. The orientation of the AL is indicated by the cross: $A$ anterior, $P$ posterior, $D$ dorsal, $V$ ventral, $L$ lateral, $M$ medial. Scale bar $25 \mu \mathrm{m}$

to segment their shape. Therefore, we did not quantify their number and did not include them in the AL atlas. From visual inspection, we estimate their number to be no less than 5-6 glomeruli per AL. All of these are located in the medial region of the ALs. However, we cannot exclude that more such glomeruli may be located in other regions of the ALs.

Two-way ANOVA revealed that there was no significant interaction of the AL type $\mathrm{x}$ sex on the total AL volume, calculated as the sum of all glomerular volumes $\left[F_{(1,34)}=0.0307, P=0.8619\right]$. These results indicate that the NB-treated contralateral ALs do not differ from the ipsilateral ones, neither in males nor in females (Fig. 5). Therefore, we calculated the mean volume as the pooled ipsilateral and contralateral AL averages: 190,287 $\pm 11,823 \mu \mathrm{m}^{3}$ in males and 204,166 $\pm 12,554 \mu \mathrm{m}^{3}$ in females. However, when the volumes of the 53 glomeruli were individually considered, two-way ANOVA showed a significant interaction of glomerulus $\times \operatorname{sex}\left[F_{(52,930)}=2.7459, P<0.0001\right]$. Post hoc comparisons of males and females showed statistical volume differences in seven glomeruli. In particular, three glomeruli were larger in females: PD1 $(P=0.00005)$, located dorso-medially in the posterior area and in close proximity to the antennal commissure, C3 $(P=0.048)$, located centrally, and PV1 $(P=0.00005)$, which is the most ventral glomerulus, placed in the posterior area.

4 glomeruli resulted larger in males than in females: AV1 $(P=0.004)$, located anteriorly, at the entrance of the antennal nerve, AD1 and D4 $(P=0.004$ and 0.000 , respectively), both located in the lateral region of the $\mathrm{AL}$ and $\mathrm{A} 1$
Fig. 3 A confocal stack of the AL of a male medfly (same preparation of $3 \mathrm{D}$ reconstructions in Fig. 9 and supplementary material), seen from an anterior perspective, as shown by NB staining. Ten sections from anterior to posterior $(\mathbf{a}-\mathbf{j})$ were selected from a total of 197 images. Sections were selected at different, and sometimes irregular, intervals (the depth within the AL neuropil is indicated in the left corner of each figure), to display all glomeruli and to restrict the number of sections displayed. The orientation of the AL is indicated: $D$ dorsal, $V$ ventral, $L$ lateral, $M$ medial. Left column displays unaltered confocal images (raw data). Middle column displays demarcated glomeruli superimposed on negative confocal images. Right column displays identified glomeruli (for terminology see text). Color coding is identical to that shown in the 3D reconstructions. Scale bar $25 \mu \mathrm{m}$

$(P=0.004)$, in the anterior part of the AL (Fig. 6). These results suggest that some odorants have a sexually related relevance, resulting in sexual dimorphism of the glomeruli relevant for their processing.

The comparison of left and right glomerular volumes reported here is based on unilateral backfills with NB, subsequently labeled by avidin-Alexa Fluor 488 or streptavidin-Cy3. The two ALs are connected by a commissure that transports the neural tracer from the ipsilateral to the contralateral AL (Fig. 1d). We noted that, in our preparations, also the contralateral antennal nerve was stained (Fig. 7), in both males and females.

Clusters of cell bodies representing somata of interneurons and projection neurons were clearly visible in the synapsin staining, the nuclei of which were stained by DAPI (Fig. 1a-d). Our results showed that unilateral (right) antennal TMR-DA backfill also resulted in some degree of contralateral staining, but not to the extent observed for NB staining (Fig. 8). In fact, staining with TMR-DA showed a lack of labeling not only in the contralateral antennal nerve, but also in some of the glomeruli in the contralateral $\operatorname{AL}(n=6)$.

\section{D atlas of antennal lobes in $C$. capitata}

The identification of single glomeruli also allowed us to compile a 3D map of the ALs, based on glomerular segmentation, both in males and females (Figs. 9, 10). To simplify recognition and visual inspection, each glomerulus has been attributed a different color. We named glomeruli in the different specimens on the basis of the same principle, as the general position is constant in the ALs, both intra- and inter-individually. The figures show labeled snapshots of an interactive 3D AL atlas of both sexes. This atlas can be downloaded as supplementary material to the present paper, and from http://neuro.uni.kn/ceratitisALatlas.

\section{Discussion}

The aim of this study was to describe the glomerular morphology of the ALs in the Mediterranean fruit fly 

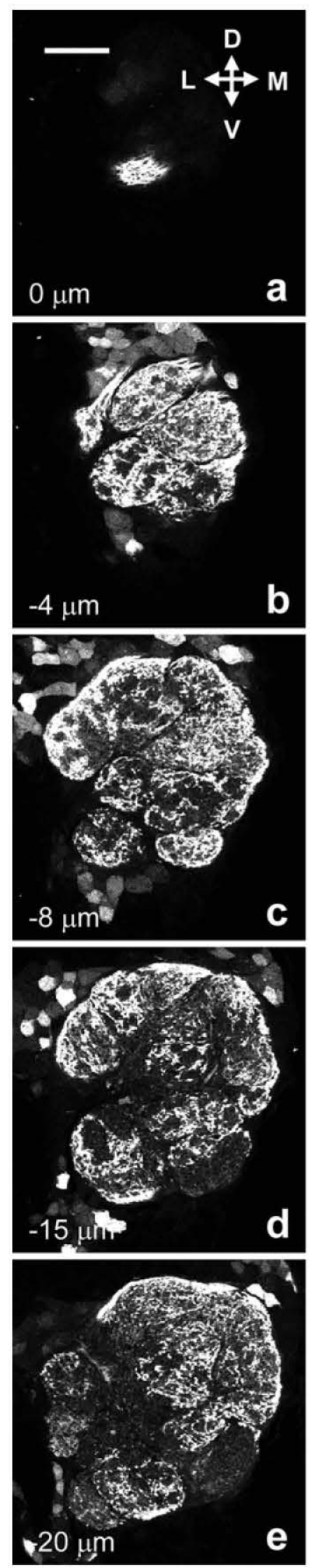
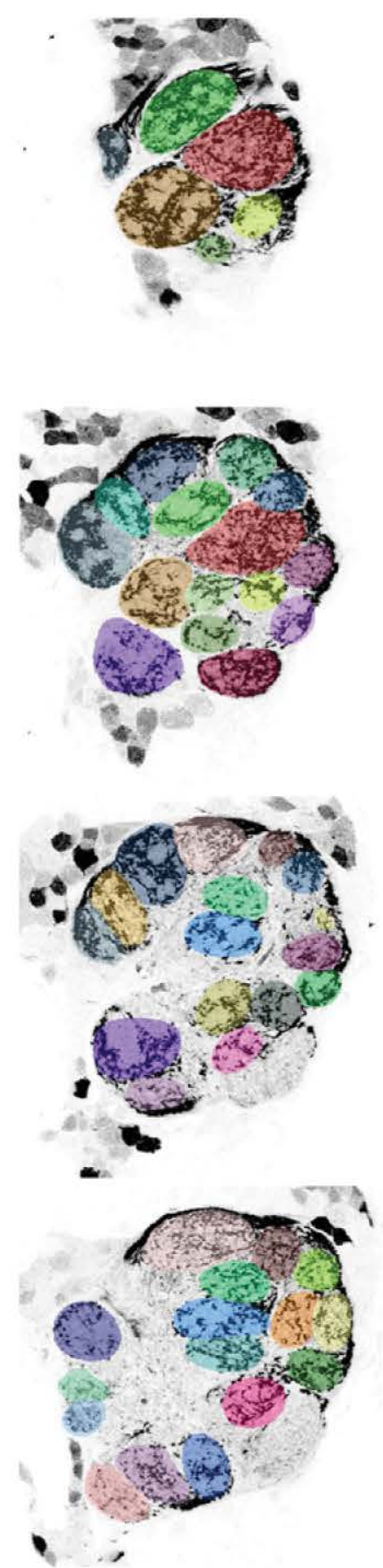

AV1
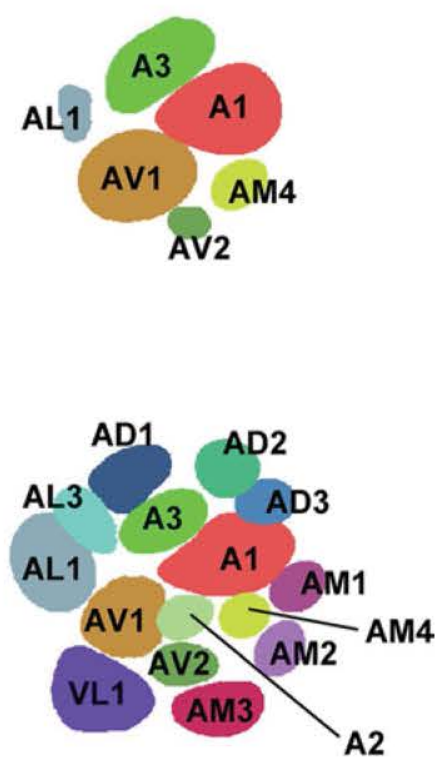

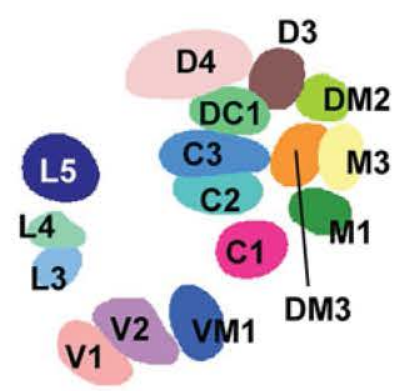



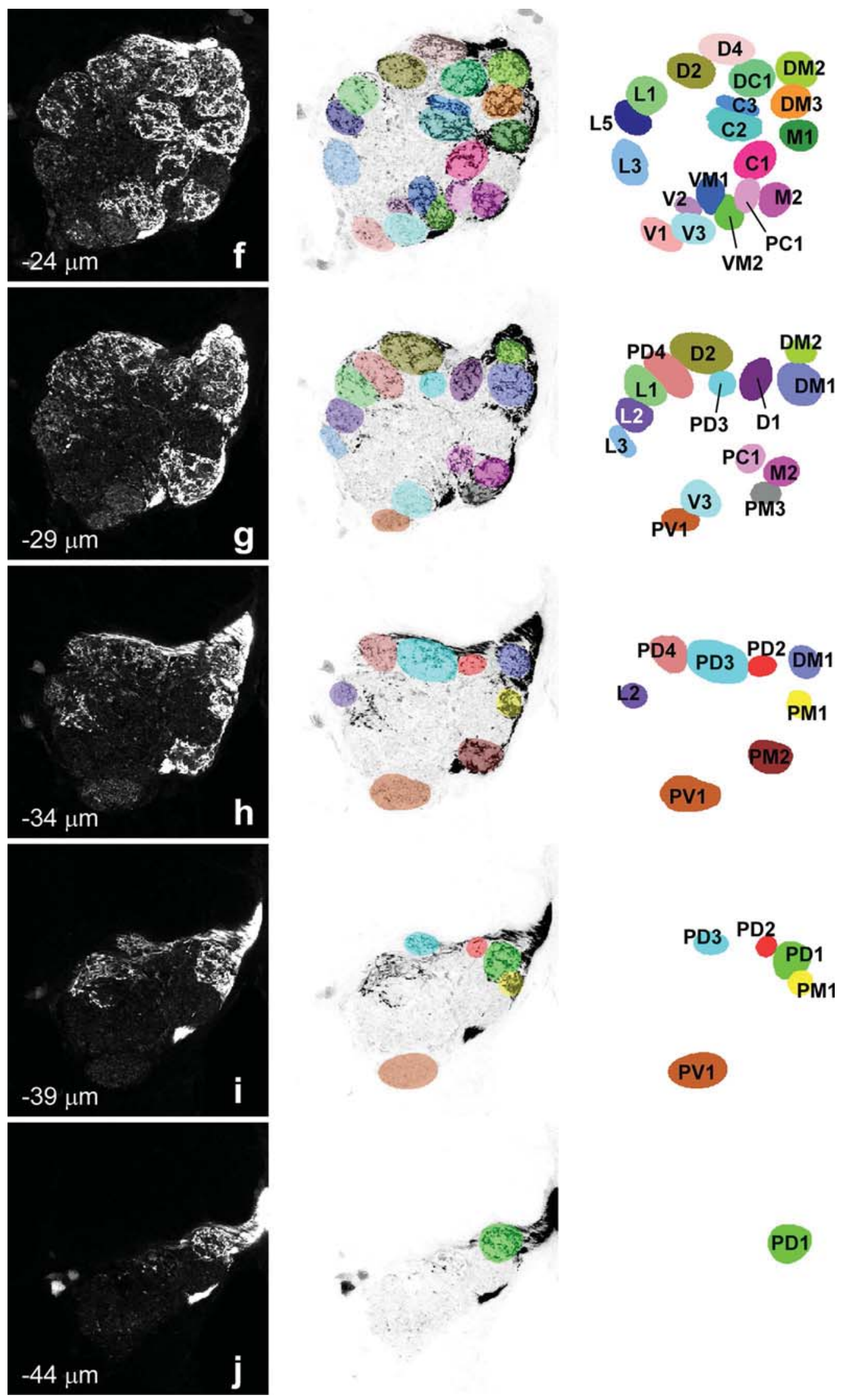

PV1

Fig. 3 continued 

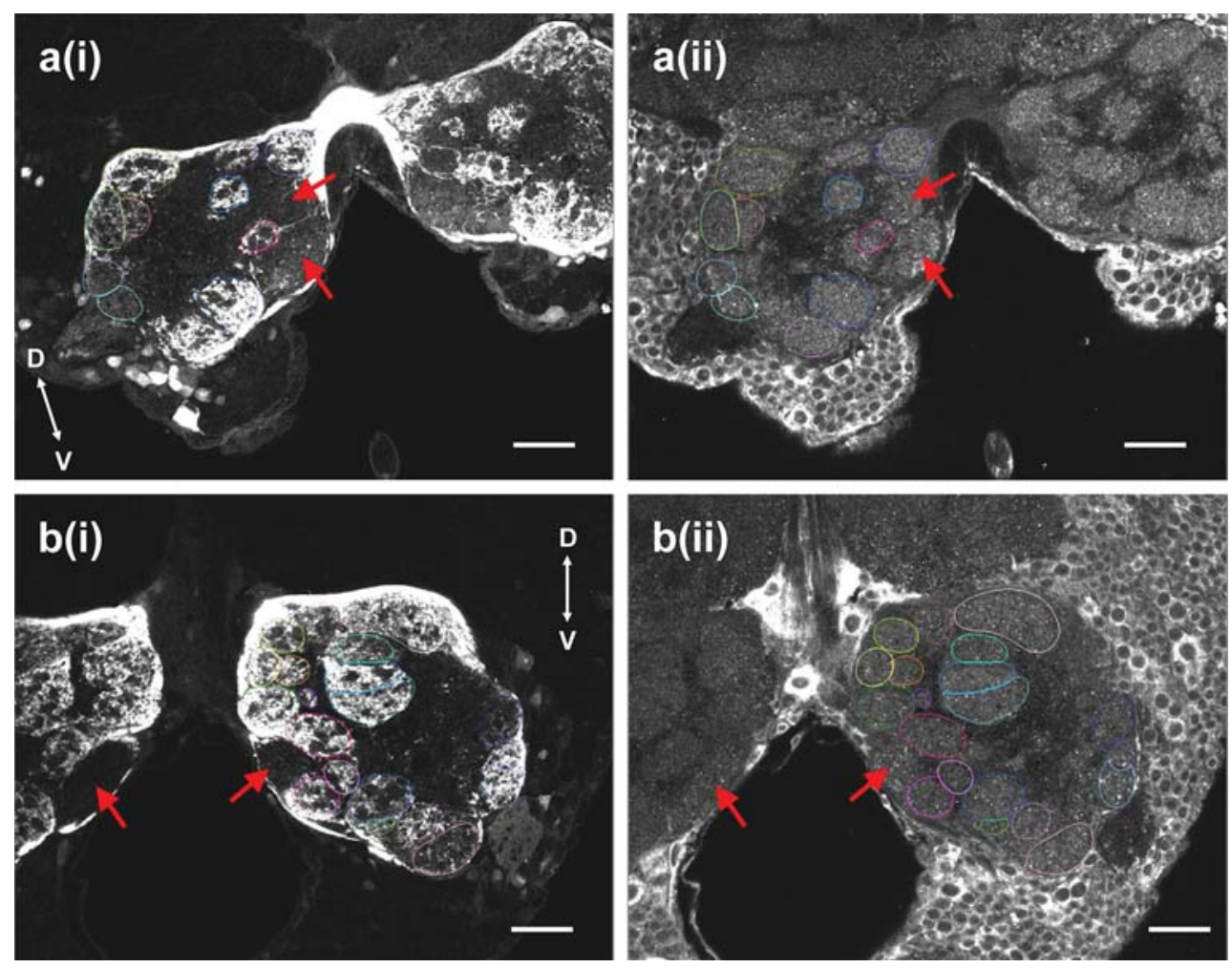

Fig. 4 Confocal images (single optical sections) of NB (i) and antisynapsin (ii) stainings from two different preparations (a and b), showing that a number of glomeruli positive to only anti-synapsin

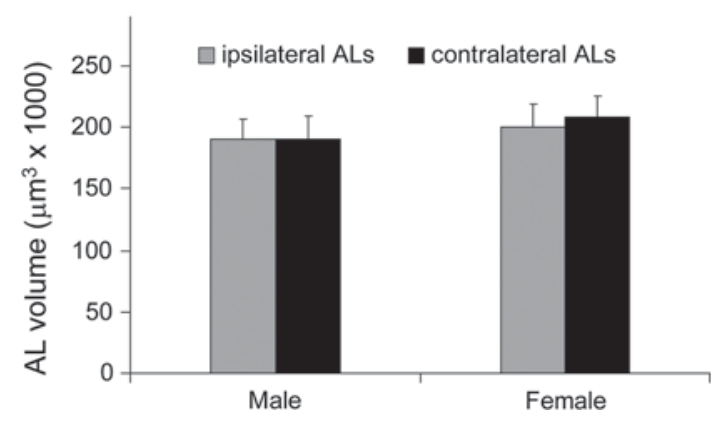

Fig. 5 Overall volume of ipsilateral and contralateral ALs (calculated as the sum of the volumes of all stained glomeruli in a given AL), in male and female medflies, following unilateral (right) antennal backfills with NB and anti-synapsin stainings. Mean values $\pm \mathrm{SE}$ (vertical bars) from 14 ALs (eight ipsi-, six contralateral) in males and 24 ALs (12 per side) in females

C. capitata. Glomeruli represent the morpho-functional units of the ALs in many species of insects (Kanzaki et al. 1989; Stocker et al. 1990; Rospars and Hildebrand 1992; Galizia et al. 1999; Laissue et al. 1999; Chiang et al. 2001; Berg et al. 2002; Anton and Rospars 2004; Ignell et al. 2005; Skiri et al. 2005; Ghaninia et al. 2007), which follow a common functional organization, but with a variable

(red arrows), are interspersed among those positive to both anti-synapsin and NB (some circled with colored outlines). The orientation of the AL is indicated: $D$ dorsal, $V$ ventral. Scale bar $25 \mu \mathrm{m}$

number across species (Rospars 1988; Schachtner et al. 2005).

\section{Technical aspects and staining quality}

After backfilling olfactory sensory axons with fluorescent tracers, we could visualize all glomeruli in the confocal image stacks. However, the borderline between one glomerulus and the next was not always easy to identify in the backfills. Here, we needed to resort to anti-synapsin counterstains to clearly distinguish single glomeruli. Synapsin labels synaptic structures (Jahn et al. 1985) and glomeruli are the places where synaptic interactions occur: thus synaptic labeling allowed us to better separate different glomeruli. Axonal afferents often crossed even neighboring glomeruli, making it difficult to pinpoint the borders. It might be that in $C$. capitata, a consistent glial sheath to separate glomeruli is less prominent. Glial sheets in the AL act as markers for axonal pathfinding (Oland and Tolbert 2011). However, these quite speculative hypotheses would need specific investigations in the future.

We note that synapsin staining also labeled the somata of many neurons around the AL, suggesting that the antibody is less specific in this species. Since synapsin labels 
Fig. 6 Normalized volume of the 53 glomeruli detected in the ipsilateral ALs, in male and female medflies, following unilateral (right) antennal backfills with NB. Mean values $\pm \mathrm{SE}$ (vertical bars) from ipsilateral glomeruli of eight ALs in males and 12 ALs in females. Asterisks indicate significant differences, for a given glomerulus, between males and females $(P<0.05$; Duncan's test subsequent to two-way ANOVA)

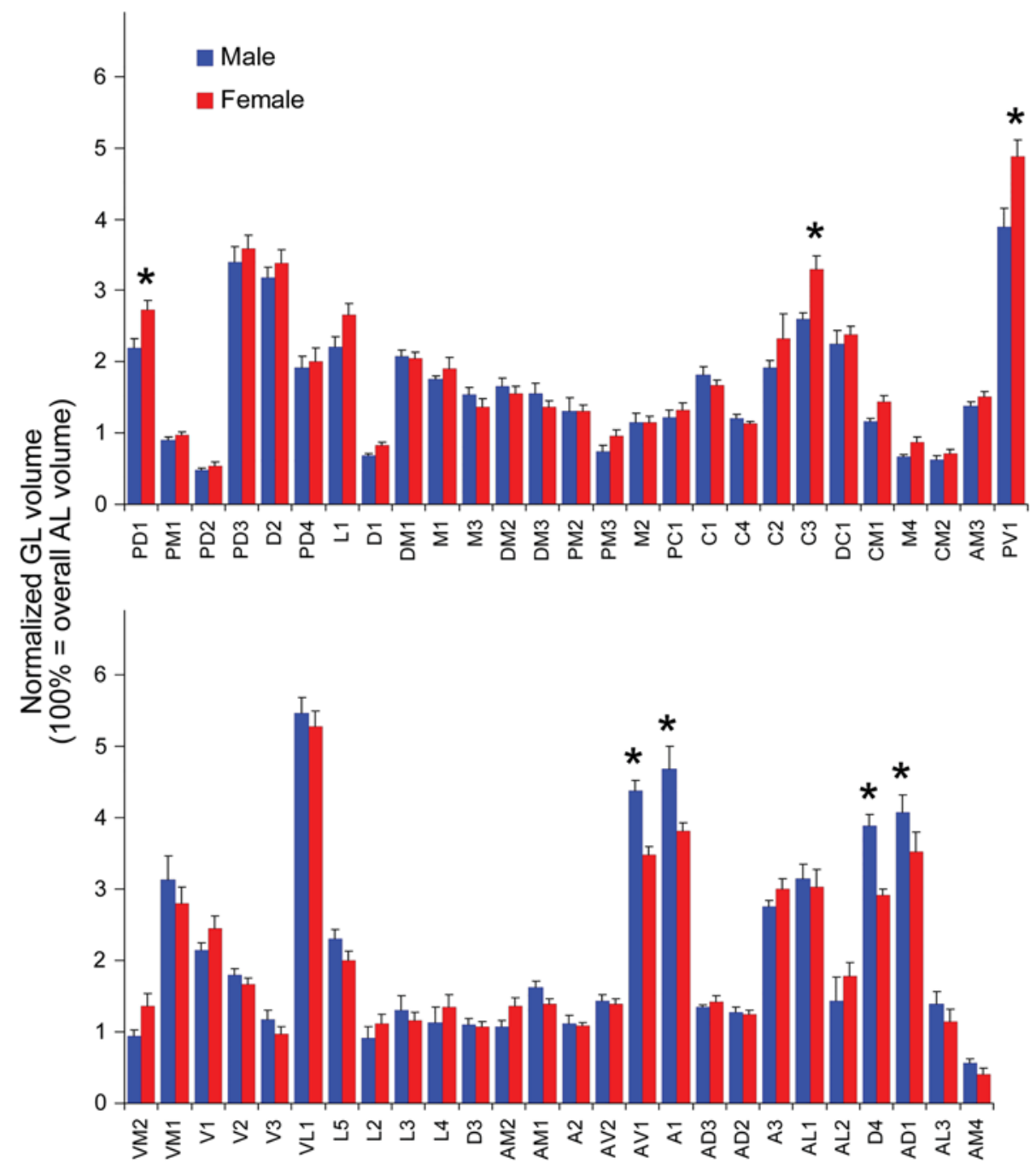

presynaptic structures, the alternative hypothesis that $\mathrm{AL}$ somata contain presynapses appears less likely.

\section{The number of glomeruli in the antennal lobe}

We have counted 53 glomeruli in $C$. capitata. It is known that the number of glomeruli may vary greatly depending on the species (Rospars 1988; Schachtner et al. 2005), but in Diptera, such as flies and mosquitoes, ALs are usually characterized by numbers ranging from around 50 to 60 (Laissue et al. 1999; Ignell et al. 2005; Ghaninia et al. 2007). Thus, the number found in $C$. capitata falls within the same range as other dipterans. There were only few cases of absent or supernumerary units. In general, the count of missing or supernumerary glomeruli in different specimens is not unusual, and this fact has been found in various insect species studied so far (Rospars and Hildebrand 1992, 2000; Galizia et al. 1999; Couton et al. 2009; Kazawa et al. 2009). The explanation for this may depend on a methodological error in the experimental and analytical procedures, as well as on individual variability. Although in $C$. capitata one cannot completely exclude an incorrect outline of glomeruli due to a methodological error, this should not be considered as the main source of difference, given the standardization of the staining protocols and the selection of good quality confocal image stacks for the count. We therefore assume that interindividual variability may be largely responsible for the presence of anomalies in the number of glomeruli. Since in Drosophila melanogaster the number of glomeruli is directly related to the number of olfactory receptors expressed by sensory neurons (Couto et al. 2005), this variability may reflect genetic variability in expressed olfactory receptor genes. It may be that this variability will have an impact on future attempts to use olfactory cues in $C$. capitata pest control.

The number of 53 glomeruli is very close to the 54 present in the closely related species D. melanogaster (Grabe et al. 2015). Other aspects of the glomerular arrangement that we found in $C$. capitata are also reminiscent of 

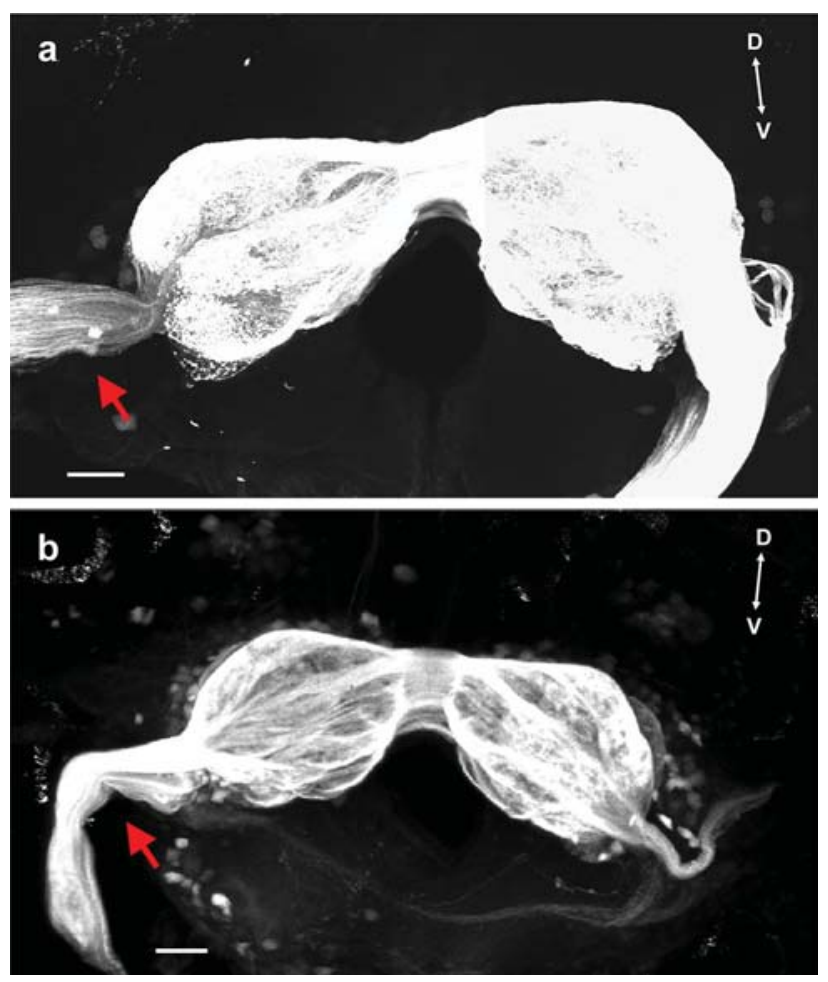

Fig. 7 Confocal planar projection views of ALs in male (a) and female (b) medflies, showing that unilateral (right) antennal backfills with NB (red arrows) stain the contralateral glomeruli and also some fibers in the contralateral antennal nerve. The orientation of the AL is indicated: $D$ dorsal, $V$ ventral. Scale bar $25 \mu \mathrm{m}$

D. melanogaster: presence of glomeruli innervated by the palps, contralateral innervation from the antennal nerve, and glomerular size (glomeruli range in size from 500 to $5000 \mu^{3}$, Grabe et al. 2015). However, the comparison with $D$. melanogaster should also serve as a cautionary one: from the first studies of the full glomerular complement (Stocker et al. 1983; Laissue et al. 1999) to the later ones (Couto et al. 2005; Endo et al. 2007; Silbering et al. 2011; Tanaka et al. 2012; Grabe et al. 2015) there have been numerous changes in glomerular number, glomerular identity, and information about innervated neurons, some of which needed genetic tools to be solved. Therefore, our atlas of $C$. capitata should be used as a tool representing the current knowledge of this species-better staining techniques, in particular genetic ones, will most likely refine our understanding of the glomerular arrangement in this species.

The combination of two different staining techniques, confocal microscopy and image analysis allowed the construction of three-dimensional maps of the ALs of $C$. capitata, based on the manual segmentation of glomeruli, in both sexes. So far, 3D reconstructions of the ALs have been made in several insects, among which other Diptera (e.g. Laissue et al. 1999; Ignell et al. 2005; Ghaninia et al. 2007; Poddighe et al. 2010; Grabe et al. 2015), but also
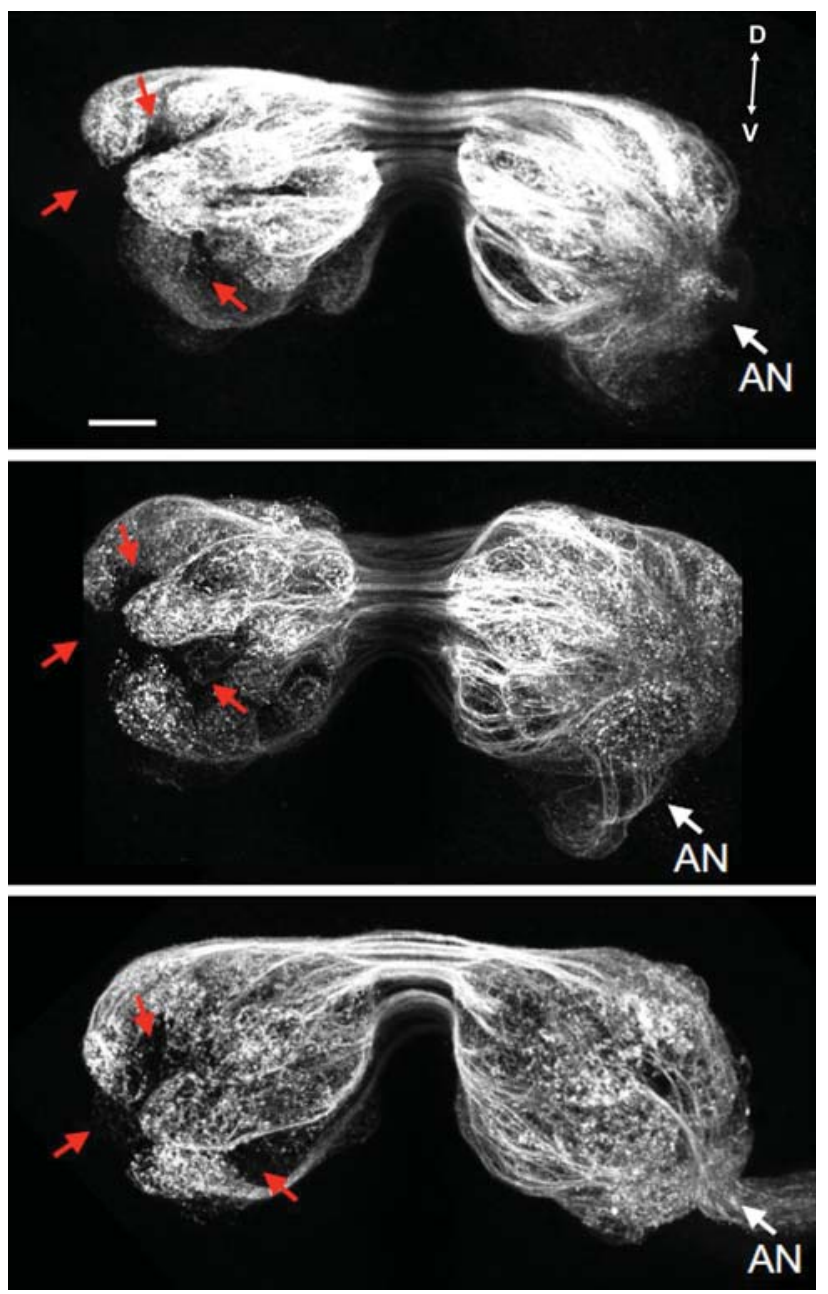

Fig. 8 Confocal planar projection views of three different preparations following unilateral (right) antennal backfills with TMR-DA, showing the high, but not complete, degree of contralateral staining and the lack of a few contralateral stained glomeruli, which is consistent through the different preparations (red arrows). Note that only the backfilled antennal nerve (AN) is labeled in each preparation. The orientation of the AL is indicated: $D$ dorsal, $V$ ventral. Scale bar $25 \mu \mathrm{m}$

Hymenoptera (e.g. Galizia et al. 1999; Smid et al. 2003), Lepidoptera (e.g. Berg et al. 2002; Greiner et al. 2004; Huetteroth and Schachtner 2005; Couton et al. 2009; Varela et al. 2009; Montgomery and Ott 2015; Grabe et al. 2015) and Coleoptera (e.g. Dreyer et al. 2010; Hu et al. 2011). The availability of reliable 3D maps of olfactory glomeruli in the AL is a necessary step to study how olfactory information is processed in the brain, in the quest to obtain a functional, chemotypic map of the ALs.

\section{Neural projections from the antennal nerve}

Beyond visualizing the glomerular structure of ALs, the NB backfills also reveal the projection patterns of axons 

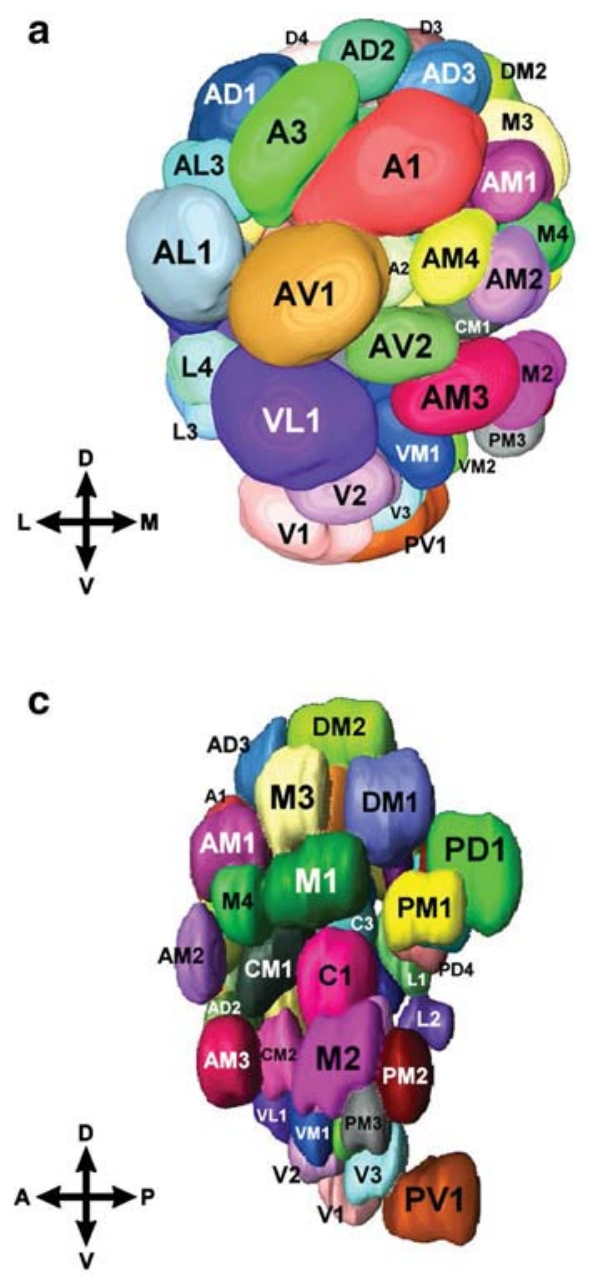

Fig. 9 Projections of 3D reconstruction of the glomeruli in the right AL of a male medfly, shown in the anterior (a), lateral (b), medial (c) and posterior (d) part of the AL. Glomeruli have been segmented with different colors to distinguish single units. Areas of more packed glomeruli are present inside the ALs. 53 glomeruli have been counted, named with capital letters and numbers according to Stocker (1994).

from the ORNs located in the antennae of the medfly. Specifically, fibers converge in the antennal nerve and enter the $\mathrm{AL}$ to form the synaptic connections with the second-order sensory neurons, which is consistent with the anatomical arrangement of olfactory pathways in other dipteran species (Stocker 1994; Poddighe et al. 2010). Interestingly, although NB was applied only unilaterally, both ipsilateral and contralateral ALs were symmetrically stained. We found that this is due to two effects: most glomeruli are innervated contralaterally by bilateral fibers projecting from ORNs, passing via the antennal commissure, to the other hemisphere. However, as in other Diptera, not all glomeruli are innervated both ipsi- and contralaterally (Fig. 8), as shown with unilateral antennal backfill using TMR-DA, which resulted in a lower level of contralateral staining b
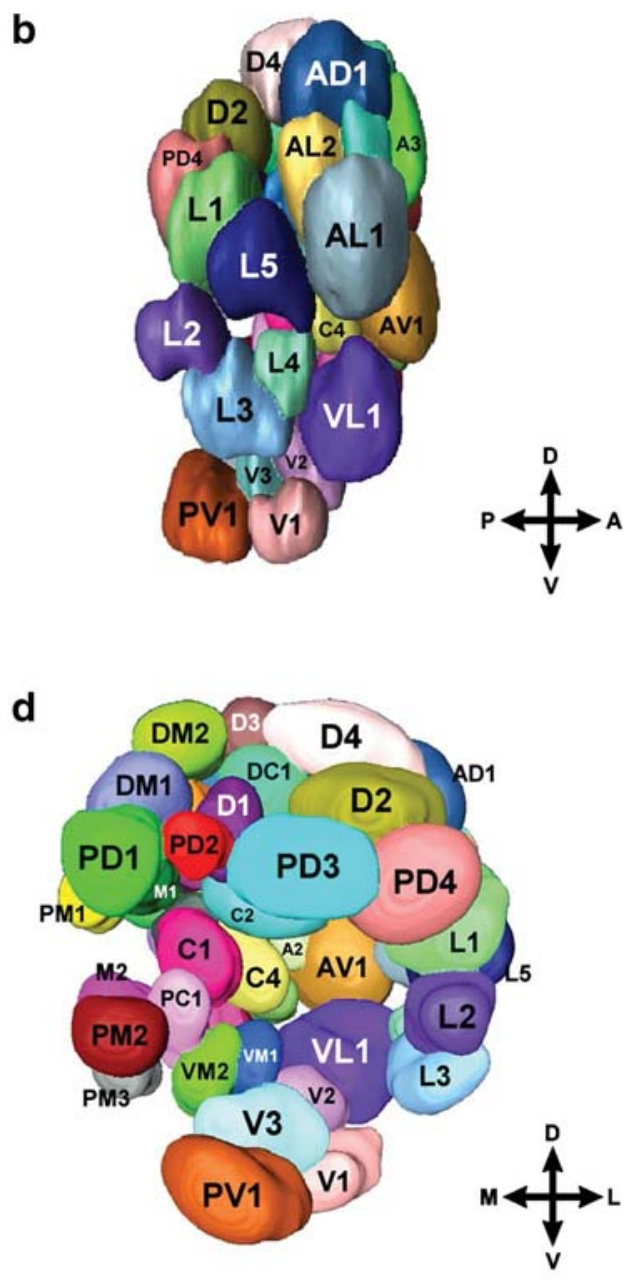

Capital letters indicate the general position of glomeruli inside the ALs, the numbers are required to distinguish glomeruli in the same region. The orientation of the $\mathrm{AL}$ is indicated by the crosses: $A$ anterior, $P$ posterior, $D$ dorsal, $V$ ventral, $L$ lateral, $M$ medial. The atlas is available as interactive $3 \mathrm{D}$ pdf file

with respect to NB. The contralateral staining observed in the case of NB could be due to the presence of gap junctions that might couple projections of ORNs among different glomeruli: in fact, gap junctions are permeable to the small NB molecules (MW 287) (Phelan et al. 1996; Haag and Borst 2005; Anava et al. 2009), but not to the ten times larger TMR-DA molecules (MW 3000). This hypothesis seems to be confirmed by the fact that, after staining the contralateral AL, the NB tracer proceeds to be incorporated also in the contralateral antennal nerve, which is not the case of unilateral TMR-DA backfills. These findings may have some implications and suggest the presence of gapjunction connections among ORNs, likely also across glomeruli in the two ALs, given that NB labels more contralateral glomeruli than TMR-DA. Possibly, fast transmission of 

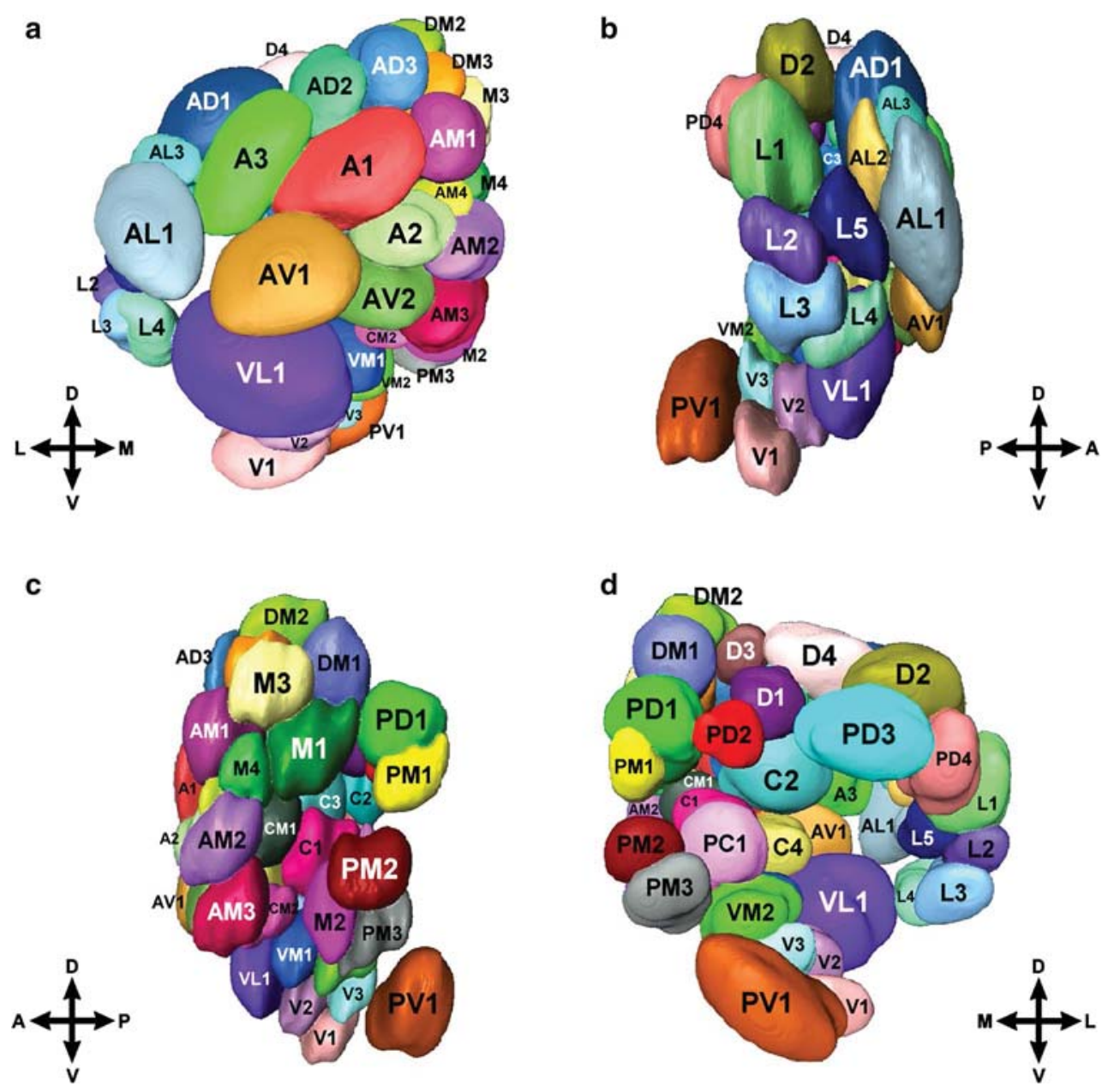

Fig. $103 \mathrm{D}$ reconstruction of the glomeruli in the right $\mathrm{AL}$ of a female medfly, shown in the anterior (a), lateral (b), medial (c) and posterior (d) part of the AL. As for the reconstruction in the male specimen, glomeruli have been visualized with different colors to dis-

information across glomeruli may be important to process information in a fast, turbulent environment, as found in the insect world, and as reflected in fast olfactory receptor responses (Szyska et al. 2014). Several electrical synapses have been found in D. melanogaster between local neurons and projection neurons, or among projection neurons (Yaksi and Wilson 2010; Wang et al. 2014). Thus, the different functional sub-circuits in the AL appear to be coupled electrically independently from each other. Further investigations are needed to elucidate these aspects.

Another interesting feature is that the two ALs are interconnected by a commissure formed by multiple nerve fascicles. The projections between the two ALs are funneled through multiple nerve fascicles in the commissure, suggesting a regional organization of the projections (Figs. 2, 8). This particular organization could reflect a functional need of the ALs, possibly providing some benefit in shortening the impulse transmission. Alternatively, it may

tinguish single units, and as in males 53 glomeruli have been counted, and named according to Stocker (1994). The orientation of the AL is indicated by the crosses: $A$ anterior, $P$ posterior, $D$ dorsal, $V$ ventral, $L$ lateral, $M$ medial. The atlas is available as interactive $3 \mathrm{D}$ pdf file

simply reflect the localization of the ALs, which in this species are rather inside the brain, and only minimally protruding outside.

Inside the ALs, some glomeruli were positive to antisynapsin, but not labeled by NB backfill from the antenna. Presumably, these glomeruli are not innervated from projections of antennal ORNs, but from sensory neurons possibly located in the sensilla of other sensory appendages such as, for instance, the maxillary palps (Stocker 1994, 2001; Anton et al. 2003; Anton and Rospars 2004; Ghaninia et al. 2007). This fact would justify a more general definition of this structure as olfactory lobe rather than antennal lobe. A future version of the atlas presented here will have to include these additional glomeruli, to give a complete map of the olfactory lobe. The supernumerary interspersed glomeruli do not seem to share gap junctions with glomeruli originating from antennal ORNs, indicating that they form a functionally distinct subpopulation within the $\mathrm{AL}$. 


\section{Sexual dimorphism in the antennal lobe}

Even though the medfly ALs were not found to vary in their overall volume between sexes, we found that they were sexually dimorphic for seven glomeruli: three (named PD1, $\mathrm{C} 3$ and PV1) were larger in females, while four resulted larger in males (AV1, AD1, D4 and A1). Usually, species characterized by sexual dimorphism in the glomerular arrangement of the ALs may show differences in the number, dimensions and/or location of glomeruli (Rospars and Hildebrand 2000). This dimorphism is generally present in species whose sexual behavior depends on pheromonemediated communication. In male moths, for example, the detection of the sex pheromone emitted by females is assured by the presence of specific sensillum types on the antennal surface. Afferents from ORNs located in these sensilla project into the AL where they form, upon entering, the first glomerular station responsible for pheromone information processing, the macroglomerular complex (MGC, Hansson et al. 1995; Berg et al. 1998). In Manduca sexta, three glomeruli have been found in females that are functionally distinct though possibly equivalent to the three MGC glomeruli in males (Rospars and Hildebrand 2000). In C. capitata, the comparison of the ALs in the two sexes showed the absence of a complex that resembles the MGC. However, one of the glomeruli located at the entrance of the AL (PD1) results to be significantly larger in volume in females than in males. Interestingly, unlike in moths, during sexual behavior of medflies the males release the pheromone to attract females for mating (Arita and Kaneshiro 1989; Jang et al. 1989; Flath et al. 1993). Functional studies should be conducted to test the association of the PD1 glomerulus with the processing of pheromone information.

In addition to PD1, the other dimorphic glomeruli larger in females than in males might be involved in a sophisticated system for the detection of suitable oviposition sites (Varela et al. 2009), while those larger in males could be linked to other odor-driven behaviors, such as the "lekking" strategies where males aggregate in large numbers (Landolt et al. 1992; Field et al. 2003). These functional aspects, that go beyond the aim of the present study, await clarification.

In conclusion, we provide a $3 \mathrm{D}$ map of the glomerular structure in $C$. capitata ALs. We hope that this work can build a necessary starting point for functional studies, to assess the relationship between the structure and the function of the olfactory pathways, and better understand how the olfactory information is processed. A functional understanding of the olfactory system in $C$. capitata will allow for a targeted development of olfactory-based control strategies.

Acknowledgments This work was supported by the MiUR-Ministero dell'Istruzione, dell'Università e della Ricerca-(prot. No.
20077RCHRW) and by the Fondazione Banco di Sardegna-Italy (prot. No. 1029/2010.0477). Dr. V. Corda gratefully acknowledges the Regional Government of Sardinia for the financial support of her $\mathrm{PhD}$ scholarship (P.O.R. Sardegna F.S.E. Operational Programme of the Autonomous Region of Sardinia, European Social Fund 2007-2013Axis IV Human Resources, Objective 1.3, Line of Activity 1.3.1.). We also wish to thank "Sardegna Ricerche, Italy" and Dr. Maria Cristina Mostallino for the use of the confocal microscopy facility. Thanks also to Drs. Silke Sachse, Veit Grabe and Jürgen Rybak for technical help in creating the 3D-pdf version of the atlas, to Dr. Marco Melis for his helpful cooperation and technical support in the experimental part of this study and to the anonymous Reviewers for their helpful criticisms and suggestions.

\section{References}

Anava S, Rand D, Zilberstein Y, Ayali A (2009) Innexin genes and gap junction proteins in the locust frontal ganglion. Insect Biochem Mol Biol 39:224-233

Anton S, Rospars JP (2004) Quantitative analysis of olfactory receptor neuron projections in the antennal lobe of the malaria mosquito, Anopheles gambiae. J Comp Neurol 475:315-326

Anton S, van Loon JJA, Meijerink J, Smid HM, Takken W, Rospars JP (2003) Central projections of olfactory receptor neurons from single antennal and palpal sensilla in mosquitoes. Arthropod Struct Dev 32:319-327

Arita LH, Kaneshiro KY (1989) Sexual selection and lek behavior in the Mediterranean fruit fly, Ceratitis capitata (Diptera: Tephritidae). Pac Sci 43:135-143

Berg BG, Almaas TJ, Bjaalie JG, Mustaparta H (1998) The macroglomerular complex of the antennal lobe in the tobacco budworm moth Heliothis virescens: specified subdivision in four compartments according to information about biologically significant compounds. J Comp Physiol A 183:669-682

Berg BG, Galizia CG, Brandt R, Mustaparta H (2002) Digital atlases of the antennal lobe in two species of tobacco budworm moths, the oriental Helicoverpa assulta (male) and the american Heliothis virescens (male and female). J Comp Neurol 446:123-134

Bigiani A, Scalera G, Crnjar R, Barbarossa IT, Magherini PC, Pietra $\mathrm{P}$ (1989) Distribution and function of the antennal olfactory sensilla in Ceratitis capitata Wied. (Diptera, Trypetidae). Boll Zool 56:305-311

Chiang AS, Liu YC, Chiu SL, Hu SH, Huang CY, Hsieh CH (2001) Three-dimensional mapping of brain neuropils in the cockroach, Diploptera punctata. J Comp Neurol 440:1-11

Cossè AA, Todd JL, Millar JG, Martìnez LA, Baker TC (1995) Electroantennographic and coupled gas chromatography-electroantennographic responses of the Mediterranean fruit fly, Ceratitis capitata, to male-produced volatiles and mango odor. J Chem Ecol 21:1823-1836

Couto A, Alenius M, Dickson BJ (2005) Molecular, anatomical, and functional organization of the Drosophila olfactory system. Curr Biol 15:1535-1547

Couton L, Minoli S, Kiêu K, Anton S, Rospars J-P (2009) Constancy and variability of identified glomeruli in antennal lobes: computational approach in Spodoptera littoralis. Cell Tissue Res 337:491-511

Crnjar R, Liscia A, Angioy AM, Tomassini Barbarossa I, Bigiani A, Scalera G, Pietra P (1988) The antennal sensilla in two tephritid flies (Ceratitis capitata and Dacus oleae): a morpho-functional study. In: Cavalloro R (ed) Fruit flies of economic importance 87. Balkema AA, Rotterdam, pp 211-216

De Meyer M, Robertson MP, Peterson AT, Mansell MW (2008) Ecological niches and potential geographical distributions of 
Mediterranean fruit fly (Ceratitis capitata) and Natal fruit fly (Ceratitis rosa). J Biogeogr 35:270-281

Diamantidis AD, Carey JR, Nakas CT, Papadopoulos NT (2011) Population-specific demography and invasion potential in medfly. Ecol Evol 1:479-488

Dreyer D, Vitt H, Dippel S, Goetz B, El Jundi B, Kollmann M, Huetteroth W, Schachtner J (2010) 3D standard brain of the red flour beetle Tribolium castaneum: a tool to study metamorphic development and adult plasticity. Front Syst Neurosci 4:3

Endo K, Aoki T, Yoda Y, Kimura K-I, Hama C (2007) Notch signal organizes the Drosophila olfactory circuitry by diversifying the sensory neuronal lineages. Nature Neurosci 10:153-160

Field SA, Kaspi R, Yuval B (2003) Why do calling medflies (Diptera: Tephritidae) cluster? Assessing the empirical evidence for models of medfly lek evolution. Fla Entomol 85:63-72

Flath RA, Jang EB, Light DM, Mon TR, Carvalho L, Binder RG, John J (1993) Volatile pheromonal emissions from the male Mediterranean fruit fly: effects of fly age and time of day. J Agric Food Chem 41:830-837

Galizia CG (2008) Insect Olfaction. In: Firestein S, Beauchamp GK (eds) The senses: a comprehensive reference, vol 4. Academic Press, San Diego, pp 725-770

Galizia CG (2014) Olfactory coding in the insect brain: data and conjectures. Eur J Neurosci 39:1784-1795

Galizia CG, Rössler W (2010) Parallel olfactory systems in insects: anatomy and function. Annu Rev Entomol 55:399-420

Galizia CG, McIlwrath SL, Menzel R (1999) A digital three-dimensional atlas of the honeybee antennal lobe based on optical sections acquired by confocal microscopy. Cell Tissue Res 295:383-394

Gasperi G, Bonizzoni M, Gomulski LM, Murelli V, Torti C, Malacrida AR, Guglielmino CR (2002) Genetic differentiation, gene flow and the origin of infestations of the medfly, Ceratitis capitata. Genetica 116:125-135

Ghaninia M, Hansson BS, Ignell R (2007) The antennal lobe of the African malaria mosquito, Anopheles gambiae-innervation and three-dimensional reconstruction. Arthropod Struct Dev 36:23-39

Grabe V, Strutz A, Baschwitz A, Hansson BS, Sachse S (2015) A digital in vivo 3D atlas of the antennal lobe of Drosophila melanogaster. J Comp Neurol 523:530-544

Greiner B, Gadenne C, Anton S (2004) Three-dimensional antennal lobe atlas of the male moth, Agrotis ipsilon: a tool to study structure-function correlation. J Comp Neurol 475:202-210

Haag J, Borst A (2005) Dye-coupling visualizes networks of largefield motion-sensitive neurons in the fly. J Comp Physiol A 191:445-454

Hansson BS, Almaas TJ, Anton S (1995) Chemical communication in heliothine moths. V. Antennal lobe projection patterns of pheromone-detecting olfactory receptor neurons in the male Heliothis virescens (Lepidoptera: Noctuidae). J Comp Physiol A 177:535-543

Headrick DH, Goeden RD (1996) Issues concerning the eradication or establishment and biological control of the Mediterranean fruit fly, Ceratitis capitata (Wiedemann) (Diptera: Tephritidae), in California. Biol Control 6:412-421

Heath RR, Landolt PJ, Tumlinson JH, Chambers DL, Murphy RE, Doolittle RE, Dueben BD, Sivinski J, Calkins CO (1991) Analysis, synthesis, formulation, and field testing of three major components of male Mediterranean fruit fly pheromone. J Chem Ecol 17:1925-1940

Hernandez MM, Sanz I, Adelantado M, Ballach S, Primo E (1996) Electroantennogram activity from antennae of Ceratitis capitata (Wied.) to fresh orange airborne volatiles. J Chem Ecol 22:1607-1617
Homberg U, Montague RA, Hildebrand JG (1988) Anatomy of antenno-cerebral pathways in the brain of the sphinx moth Manduca sexta. Cell Tissue Res 254:255-281

Homberg U, Christensen TA, Hildebrand JG (1989) Structure and function of the deutocerebrum in insects. Annu Rev Entomol 34:477-501

Hu J-H, Wang Z-Y, Sun F (2011) Anatomical organization of antennal-lobe glomeruli in males and females of the scarab beetle Holotrichia diomphalia (Coleoptera: Melolonthidae). Arthropod Struct Dev 40:420-428

Huetteroth W, Schachtner J (2005) Standard three-dimensional glomeruli of the Manduca sexta antennal lobe: a tool to study both developmental and adult neuronal plasticity. Cell Tissue Res 319:513-524

Ignell R, Dekker T, Ghaninia M, Hansson BS (2005) Neuronal architecture of the mosquito deutocerebrum. J Comp Neurol 493:207-240

Ito K, Suzuki K, Estes P, Ramaswami M, Yamamoto D, Strausfeld NJ (1998) The organization of extrinsic neurons and their implications in the functional roles of the mushroom bodies in Drosophila melanogaster Meigen. Learn Mem 5:52-77

Ito K, Shinomiya K, Ito M, Armstrong J, Boyan G, Hartenstein V, Harzsch S, Heisenberg M, Homberg U, Jenett A, Keshishian H, Restifo LL, Rössler W, Simpson JH, Strausfeld NJ, Strauss R, Vosshall LB (2014) A systematic nomenclature for the insect brain. Neuron 81:755-765

Jahn R, Schiebler W, Ouimet C, Greengard P (1985) A 38,000-dalton membrane protein (p38) present in synaptic vesicles. Proc Natl Acad Sci USA 82:4137-4141

Jang EB (1995) Effects of mating and accessory gland injections on olfactory-mediated behavior in the female Mediterranean fruit fly, Ceratitis capitata. J Insect Physiol 41:705-710

Jang EB, Light DM, Flath RA, Nagata JT, Mon TR (1989) Electroantennogram responses of the Mediterranean fruit fly, Ceratitis capitata to identified volatile constituents from calling males. Entomol Exp Appl 50:7-19

Jang EB, Light DM, Binder RG, Flath RA, Carvalho LA (1994) Attraction of female Mediterranean fruit flies to the five major components of male-produced pheromone in a laboratory flight tunnel. J Chem Ecol 20:9-20

Kanzaki R, Arbas EA, Strausfeld NJ, Hildebrand JG (1989) Physiology and morphology of projection neurons in the antennal lobe of the male moth Manduca sexta. J Comp Physiol A 165:427-453

Katsoyannos BI, Kouloussis NA, Papadopoulos NT (1997) Response of Ceratitis capitata to Citrus chemicals under semi-natural conditions. Entomol Exp Appl 82:181-188

Kazawa T, Namiki S, Fukushima R, Terada M, Soo K, Kanzaki R (2009) Constancy and variability of glomerular organization in the antennal lobe of the silkmoth. Cell Tissue Res 336:119-136

Knaden M, Strutz A, Ahsan J, Sachse S, Hansson BS (2012) Spatial representation of odorant valence in an insect brain. Cell Rep 1:392-399

Laissue PP, Reiter C, Hiesinger PR, Halter S, Fischbach KF, Stocker RF (1999) Three-dimensional reconstruction of the antennal lobe in Drosophila melanogaster. J Comp Neurol 405:543-552

Landolt PJ, Heath RR, Chamber DL (1992) Oriented flight responses of female Mediterranean fruit flies to calling males, odor of calling males, and a synthetic pheromone blend. Entomol Exp Appl 65:259-266

Larsen JR, Dethier VG, Broadbent AH (1976) Brain of the black blowfly, Phormia regina Meigen (Diptera: Calliphoridae). Int J Insect Morphol Embryol 5:79-106

Levinson H, Levinson A, Muller K (1990) Influence of some olfactory and optical properties of fruits on host location by the 
Mediterranean fruit fly (Ceratitis capitata Wied.). J Appl Entomol 109:44-54

Light DM, Jang EB, Dickens JC (1988) Electroantennogram responses of the Mediterranean fruit fly, Ceratitis capitata, to a spectrum of plant volatiles. J Chem Ecol 14:159-180

Light DM, Jang EB, Flath RA (1992) Electroantennogram responses of the Mediterranean fruit fly, Ceratitis capitata, to the volatile constituents of nectarines. Entomol Exp Appl 63:13-26

Liquido NJ, Cunningham RT, Nakagawa A (1990) Host plants of Mediterranean fruit fly (Diptera: Tephritidae) on the island of Hawaii (1949-1985 survey). J Econ Entomol 83:1863-1878

Malacrida AR, Gomulski LM, Bonizzoni M, Bertin S, Gasperi G, Guglielmino CR (2007) Globalization and fruitfly invasion and expansion: the medfly paradigm. Genetica 131:1-9

Mayo I, Anderson M, Burguete J, Robles Chillida EM (1987) Structure of superficial chemoreceptive sensilla on the third antennal segment of Ceratitis capitata (Wiedemann) (Diptera: Tephritidae). Int J Insect Morphol Embryol 16:131-141

Montgomery SH, Ott SR (2015) Brain composition in Godyris zavaleta, a diurnal butterfly, reflects an increased reliance on olfactory information. J Comp Neurol 523:869-891

Oland LA, Tolbert LP (2011) Roles of glial cells in neural circuit formation: insights from insects. Glia 59:1273-1295

Papadopoulos NT, Katsoyannos BI, Kouloussis NA, Hendrichs J (2001) Effect of orange peel substances on mating competitiveness of male Ceratitis capitata. Entomol Exp Appl 99:253-261

Phelan P, Nakagawa M, Wilkin MB, Moffat KG, O'Kane CJ, Davies JA, Bacon JP (1996) Mutations in shaking-B prevent electrical synapse formation in the Drosophila giant fiber system. J Neurosci 16:1101-1113

Poddighe S, Dekker T, Scala A, Angioy AM (2010) Olfaction in the female sheep botfly. Naturwissenschaften 97:827-835

Rospars JP (1988) Structure and development of the insect antennodeutocerebral system. Int J Insect Morphol Embriol 17:243-294

Rospars JP, Hildebrand JG (1992) Anatomical identification of glomeruli in the antennal lobes of the male sphinx moth Manduca sexta. Cell Tissue Res 270:205-227

Rospars JP, Hildebrand JG (2000) Sexually dimorphic and isomorphic glomeruli in the antennal lobes of the sphinx moth Manduca sexta. Chem Senses 25:119-129

Schachtner J, Schmidt M, Homberg U (2005) Organization and evolutionary trends of primary olfactory brain centers in Tetraconata (Crustacea + Hexapoda). Arthropod Struct Dev 34:257-299

Shelly TE (2005) Exposure to $\alpha$-copaene-containing fruits enhances the mating success of males from a mass-reared, genetic sexing strain of the Mediterranean fruit fly (Diptera: Tephritidae). Proc Hawaiian Entomol Soc 37:39-48

Shelly TE, Kennelly S (2002) Influence of male diet on male mating success and longevity and female remating in the Mediterranean fruit fly (Diptera: Tephritidae) under laboratory conditions. Fla Entomol 85:572-579

Shelly TE, McInnis DO (2003) Influence of adult diet on the mating success and survival of male Mediterranean fruit flies (Diptera: Tephritidae) from two mass-rearing strains on field-caged host trees. Fla Entomol 86:340-344

Shelly TE, Whittier TS, Villalobos EM (1996) Trimedlure affects mating success and mate attraction in male Mediterranean fruit flies. Entomol Exp Appl 78:181-185

Shelly TE, McInnis DO, Pahio E, Edu J (2004) Aromatherapy in the Mediterranean fruit fly (Diptera: Tephritidae): sterile males exposed to ginger root oil in prerelease storage boxes display increased mating competitiveness in field-cage trials. J Econ Entomol 97:846-853
Shelly T, Edu J, Smith E, Hoffman K, War M, Santos R, Favela A, Garagliano R, Ibewiro B, McInnis D (2007) Aromatherapy on a large scale: exposing entire adult holding rooms to ginger root oil increases the mating competitiveness of sterile males of the Mediterranean fruit fly in field cage trials. Entomol Exp Appl 123:193-201

Shelly TE, War M, Favela A (2008) Exposing entire adult holding rooms containing sterile male Mediterranean fruit flies to orange oil increases the mating success of those males in field-cage trials. Fla Entomol 91:686-689

Silbering AF, Rytz R, Grosjean Y, Abuin L, Ramdya P, Jefferis GSXE, Benton R (2011) Complementary function and integrated wiring of the evolutionarily distinct Drosophila olfactory subsystems. J Neurosci 31:13357-13375

Skiri HT, Rø H, Berg BG, Mustaparta H (2005) Consistent organization of glomeruli in the antennal lobes of related species of heliothine moths. J Comp Neurol 491:367-380

Smid HM, Bleeker MA, van Loon JJ, Vet LE (2003) Three-dimensional organization of the glomeruli in the antennal lobe of the parasitoid wasps Cotesia glomerata and $C$. rubecula. Cell Tissue Res 312:237-248

Sollai G, Altea N, Masala C, Loy F, Liscia A, Crnjar R, Solari P (2010) EAG responses of the medfly Ceratitis capitata to fruit and foliage headspace of host-plants: a comparison between wild and lab reared insect populations. Abstract from the XXth Congress of European Chemoreception Research Organization, ECRO-2010, Avignon. Chem Senses 36:E79

Stocker RF (1994) The organization of the chemosensory system in Drosophila melanogaster: a review. Cell Tissue Res 275:3-26

Stocker RF (2001) Drosophila as a focus in olfactory research: mapping of olfactory sensilla by fine structure, odor specificity, odorant receptor expression, and central connectivity. Microsc Res Tech 55:284-296

Stocker RF, Singh RN, Schorderet M, Siddiqi O (1983) Projection patterns of different types of antennal sensilla in the antennal glomeruli of Drosophila melanogaster. Cell Tissue Res 232:237-248

Stocker RF, Lienhard MC, Borst A, Fischbach KF (1990) Neuronal architecture of the antennal lobe in Drosophila melanogaster. Cell Tissue Res 262:9-34

Strausfeld NJ, Hildebrand JG (1999) Olfactory systems: common design, uncommon origins? Curr Opin Neurobiol 9:634-639

Szyska P, Gerkin RC, Galizia CG, Smith BH (2014) High-speed odor transduction and pulse tracking by insect olfactory receptor neurons. Proc Natl Acad Sci USA 111:16925-16930

Tanaka NK, Endo K, Ito K (2012) Organization of antennal lobeassociated neurons in adult Drosophila melanogaster brain. J Comp Neurol 520:4067-4130

Varela N, Couton L, Gemeno C, Avilla J, Rospars J-P, Anton S (2009) Three-dimensional antennal lobe atlas of the oriental fruit moth, Cydia molesta (Busck) (Lepidoptera: Tortricidae): comparison of male and female glomerular organization. Cell Tissue Res 337:513-526

Wang K, Gong J, Wang Q, Li H, Cheng Q, Liu Y, Zeng S, Wang Z (2014) Parallel pathways convey olfactory information with opposite polarities in Drosophila. Proc Natl Acad Sci USA 111:3164-3169

Yaksi E, Wilson RI (2010) Electrical coupling between olfactory glomeruli. Neuron 67:1034-1047 